\title{
Commentary Extending international sepsis epidemiology: the impact of organ dysfunction
}

\author{
Annette M Esper and Greg S Martin
}

Division of Pulmonary, Allergy and Critical Care, Emory University School of Medicine, 49 Jesse Hill Jr Drive [FOB], Atlanta, GA 30303, USA

Corresponding author: Annette M Esper, aesper@emory.edu

Published: 23 February 2009

Critical Care 2009, 13:120 (doi:10.1186/cc7704)

This article is online at http://ccforum.com/content/13/1/120

(c) 2009 BioMed Central Ltd

See related research by Blanco et al., http://ccforum.com/content/12/6/R158

\begin{abstract}
In the previous issue of Critical Care, Blanco and colleagues contributed to a growing body of literature on the international epidemiology of severe sepsis. Taken together, these studies confirm that the sepsis incidence is high, that the development of organ dysfunction is a major determinant of mortality and that the occurrence of organ dysfunction is influenced by chronic comorbid medical conditions. It is clear that early detection of organ dysfunction and serial sequential organ dysfunction scoring provides us with the best chance to optimize clinical care. Identifying factors that contribute to the development of organ dysfunction in sepsis will lead to the development of new treatment modalities that will reduce mortality. Future studies must therefore focus on the impact of new treatment modalities for preventing progression to multiple organ dysfunction syndrome and consequent mortality in sepsis.
\end{abstract}

The sepsis syndrome is a disease entity of universal impact. Many studies have reported on the epidemiology of sepsis, and from these findings we are constantly informed that sepsis is a disease that deserves attention. In past years, there have been advances in our understanding of sepsis, ranging from studies of epidemiology to pathophysiology to risk prediction and outcome. Overall, we are in agreement that the sepsis syndrome is common, expensive and associated with a remarkably high mortality rate.

In the previous issue of Critical Care, Blanco and colleagues added to our knowledge from their prospective, observational, multicenter cohort study, evaluating the epidemiology of severe sepsis in intensive care units (ICUs) in Spain [1]. In this study they report a high incidence of severe sepsis in the ICUs, accompanied by high mortality both in the ICU and at hospital discharge. Their study gives us insight into the impact of severe sepsis on organ dysfunction and mortality, although the study was conducted prior to the Surviving Sepsis Campaign guidelines and prior to availability of recombinant human activated protein $\mathrm{C}$ in Spain, both of which may influence the results.

The current study adds to a robust and growing body of literature on the international epidemiology of sepsis. These studies confirm the increasing incidence of severe sepsis; and although mortality is decreasing, it remains unacceptably high at $25 \%$ to $45 \%$ [2-4]. Numerous factors are thought to contribute to the increasing incidence, including advancing age, immunosuppression and multidrug-resistant infections. The current study found an incidence of severe sepsis of $12.4 \%$, which is similar to previous ICU-based sepsis cohort studies [5]. Although there is documented variation in sepsis incidence between ICUs and between countries [6], the population-based estimates of sepsis incidence are remarkably constant worldwide [7]. Similarly, reductions in mortality have not been attributed to sepsis-specific knowledge or interventions, but rather to more general improvements in acute and intensive hospital care. With this background, what have we learned over the years about this disease process?

The sepsis syndrome exists along a disease continuum that includes severe sepsis and septic shock, based on the occurrence of sepsis-related organ dysfunction. Multiple organ dysfunction syndrome (MODS) is the leading cause of morbidity and mortality for patients admitted to an ICU [8], and develops in about $15 \%$ of all ICU admissions. Some have speculated that comorbid medical conditions, such as cancer, HIV, diabetes and alcohol abuse may have an effect on disease progression in sepsis. We have found that comorbidities influence the risk and outcome of sepsis [9] and that cumulative comorbidities are associated with greater organ dysfunction $[2,10]$. The evolution of organ dysfunction throughout the septic process provides us with critical

$\mathrm{ICU}=$ intensive care unit; MODS $=$ multiple organ dysfunction syndrome. 
information on the host response, pathophysiology and optimal application of specific therapies.

Given that organ dysfunction is responsible for morbidity and mortality in sepsis, its early recognition is critical. Interestingly, Blanco and colleagues found that $78 \%$ of sepsis patients had greater than two dysfunctional organ systems at the time of sepsis diagnosis, raising concern about how early and how effectively we diagnosis sepsis. Perhaps a reappraisal of current organ dysfunction scoring and its utility is therefore necessary. Organ dysfunction scoring systems satisfactorily predict ICU mortality and may additionally provide insight into the evolving nature of organ dysfunction, helping to identify treatment effects [11]. In the current study, the logistic organ dysfunction system and sepsis-related organ failure assessment scales were used to define organ dysfunction, and both scores were independently associated with mortality. The application of serial organ dysfunction assessments may better inform us about an individual patient's illness and their response to treatment. For these reasons it is therefore time to develop even more useful organ dysfunction scores.

Blanco and colleagues' study also gives us a view of morbidity and mortality with sepsis that resonates with prior studies. The development and persistence of MODS is the major contributor to death in most instances. In the current study, mortality at 28 days was $48 \%$, but there was a high prevalence of MODS and a high early mortality ( $<48$ hours) of $15 \%$. Factors associated with early death included hematologic and hepatic failure, inappropriate antibiotic treatment, the logistic organ dysfunction system score and acquisition site of infection, similar to prior studies [5]. Factors associated with increased hospital mortality included severity of organ dysfunction, presence and severity of comorbid conditions, age and chronic alcohol abuse. In analyzing further the factors that may contribute to increased mortality, the authors focused on the evolution of organ dysfunction and found that the mean sepsis-related organ failure assessment score decreased with time in survivors when compared with nonsurvivors. This observation confirms the relationship between mortality and the persistence and progression of organ failure documented in other studies [12].

An understanding of the epidemiology of the sepsis syndrome is vital for therapeutic improvements. The complexity of the syndrome necessitates data obtained from large epidemiological studies to better understand the factors that facilitate early identification of patients at risk for progressing further along the disease spectrum. Various therapeutic modalities have been introduced that have an effect on mortality, including early antibiotic use and early goal-directed therapy - a finding corroborated by meta-analysis [13]. The high incidence of MODS at diagnosis and the high early mortality in the current study raise the question of how to achieve a timely sepsis diagnosis in order to optimize management. The Surviving Sepsis Campaign has estab- lished guidelines that utilize sepsis screening and the application of care bundles to meet this goal [14]. The authors could extend their current study to determine whether the implementation of new therapeutic modalities and the Surviving Sepsis Campaign has impacted severe sepsis outcomes in Spain, as suggested by recent data [15], using an extended longitudinal real-world cohort study.

The study by Blanco and colleagues reiterates what we have learned from prior studies on severe sepsis. We must now focus on identifying factors that can be manipulated to achieve our goal of reducing incidence and improving survival. To that end, it is useful to know the incidence in various populations, which will facilitate identifying factors that differ between these populations, and thus may account for the differences in incidence and outcome. From the current study, timely and accurate detection of organ dysfunction and assessment of comorbid conditions that may alter the host response is vital. Furthermore, the development of new modalities necessitates studies investigating the effects these advances have on the outcomes of critically ill patients and on the quality of care delivered. Only then can we come closer to maximally affecting outcomes in sepsis.

\section{Competing interests}

The authors declare that they have no competing interests.

\section{References}

1. Blanco J, Muriel-Bombín A, Sagredo V, Taboada F, Gandía F, Tamayo L, Collado J, Garcia-Labattut, Carriedo D, Valledor M, De Frutos M, López MJ, Caballero A, Guerra J, Álvarez B, Mayo A, Villar J, the Grupo de Estudios y Análisis en Cuidados Intensivos (G.R.E.C.I.A.): Incidence, organ dysfunction and mortality in severe sepsis: a Spanish multicenter study. Crit Care 2008, 12:R158.

2. Martin GS, Mannino DM, Eaton S, Moss M: The epidemiology of sepsis in the United States from 1979 through 2000. N Engl J Med 2003, 348:1546-1554.

3. Angus DC, Linde-Zwirble WT, Lidicker J, Clermont G, Carcillo J, Pinsky MR: Epidemiology of severe sepsis in the United States: analysis of incidence, outcome, and associated costs of care. Crit Care Med 2001, 29:1303-1310.

4. Harrison DA, Welch CA, Eddleston JM: The epidemiology of severe sepsis in England, Wales and Northern Ireland, 1996 to 2004: secondary analysis of a high quality clinical database, the ICNARC Case Mix Programme Database. Crit Care 2006, 10:R42.

5. Brun-Buisson C, Doyon F, Carlet J, Dellamonica P, Gouin F, Lepoutre A, Mercier JC, Offenstadt G, Regnier B: Incidence, risk factors, and outcome of severe sepsis and septic shock in adults. A multicenter prospective study in intensive care units. French ICU Group for Severe Sepsis. JAMA 1995, 274:968974.

6. Vincent JL, Sakr Y, Sprung CL, Ranieri VM, Reinhart K, Gerlach H, Moreno R, Carlet J, Le Gall JR, Payen D: Sepsis in European intensive care units: results of the SOAP study. Crit Care Med 2006, 34:344-353.

7. Danai $P$, Martin GS: Epidemiology of sepsis: recent advances. Curr Infect Dis Rep 2005, 7:329-334.

8. Marshall JC, Cook DJ, Christou NV, Bernard GR, Sprung CL, Sibbald WJ: Multiple organ dysfunction score: a reliable descriptor of a complex clinical outcome. Crit Care Med 1995, 23:1638-1652.

9. Danai PA, Moss M, Mannino DM, Martin GS: The epidemiology of sepsis in patients with malignancy. Chest 2006, 129:14321440.

10. Esper AM, Moss M, Lewis CA, Nisbet R, Mannino DM, Martin GS: 
The role of infection and comorbidity: factors that influence disparities in sepsis. Crit Care Med 2006, 34:2576-2582.

11. Khwannimit B: A comparison of three organ dysfunction scores: MODS, SOFA and LOD for predicting ICU mortality in critically ill patients. J Med Assoc Thai 2007, 90:1074-1081.

12. Alberti C, Brun-Buisson C, Chevret S, Antonelli M, Goodman SV, Martin C, Moreno R, Ochagavia AR, Palazzo M, Werdan K, Le Gall JR: Systemic inflammatory response and progression to severe sepsis in critically ill infected patients. Am J Respir Crit Care Med 2005, 171:461-468.

13. Kern JW, Shoemaker WC: Meta-analysis of hemodynamic optimization in high-risk patients. Crit Care Med 2002, 30:16861692.

14. Dellinger RP, Levy MM, Carlet JM, Bion J, Parker MM, Jaeschke $R$, Reinhart K, Angus DC, Brun-Buisson C, Beale R, Calandra T, Dhainaut JF, Gerlach H, Harvey M, Marini JJ, Marshall J, Ranieri M, Ramsay G, Sevransky J, Thompson BT, Townsend S, Vender JS, Zimmerman JL, Vincent JL: Surviving Sepsis Campaign: international guidelines for management of severe sepsis and septic shock: 2008. Intensive Care Med 2008, 34:17-60.

15. Ferrer R, Artigas A, Levy MM, Blanco J, Gonzalez-Diaz G, Garnacho-Montero J, lbanez J, Palencia E, Quintana M, de la TorrePrados MV: Improvement in process of care and outcome after a multicenter severe sepsis educational program in Spain. JAMA 2008, 299:2294-2303. 